\title{
PEMAHAMAN DAN PENGGUNAAN VARIASI BAHASA PRANCIS BIDANG AGROWISATA BAGI STAKEHOLDER PARIWISATA DI MAKASSAR SEBAGAI UPAYA PENINGKATAN PELAYANAN KEPADA TURIS MANCANEGARA
}

\author{
${ }^{1}$ Muhammad Hasyim, ${ }^{2}$ Andi Muhammad Akhmar, ${ }^{3}$ Prasuri Kuswarini, ${ }^{4}$ Masdiana \\ Universitas Hasanuddin ${ }^{1,2,3}$ \\ hasyimfrance@unhas.ac.id \\ akhmar@unhas.ac.id \\ p.kuswarini@fib.unhas.ac.id \\ masdiana@fs.unhas.ac.id
}

\begin{abstract}
Abstrak
The monetary crisis since 1998 that hit Indonesia, has a negative impact on the tourism business, which is marked by a decrease in the number of foreign tourist visits that have an impact on tourism economic activities. On that basis, in 2018 the Indonesian government has emphasized the importance of empowering existing natural potential and becoming a regional characteristic as a potential tourism activity. One of the programs launched by the area in Toraja is the improvement and management of agrotourism (agrotourism) with the image of the Toraja region, as the Coffee Regency. Based on the results of the research, one solution was found, namely the need for a variant of a tourist attraction that supports the main tourist attractions of Toraja, Tradition Culture (graves) and Tongkonan traditional houses. The potential variation of objects to be developed in Toraja is agrotourism which so far has not been fully developed. In developing agrotourism in Toraja, it is important to improve services from aspects of specific field languages (agrotourism), one of which is French. For this reason, the solution that can be given to tourism stakeholders is to provide language skills training through understanding and using French variants in agro-tourism. The results of this workshop show that participants are able to explain vocabulary and speak (communicate orally) in French in the field of agrotourism Keywords: French, agrotourism, Toraja, foreign tourists
\end{abstract}

\section{A. PENDAHULUAN}

Hasil penelitian BMIS tahun 2016 yang telah kami lakukan menyimpulkan bahwa wisata budaya tradisi (Rambusolo) sebagai karakterisitik paririwasata di Toraja tidaklah cukup untuk meningkatkan daya tarik wisatawan, khususnya wisatawan mancanegara. Solusi yang diberikan dari hasil penelitian itu adalah pentingnya pihak pemerintah daerah Toraja (Tanah Toraja dan Toraja Utara) mengembangkan agrowisata, dalam hal ini kopi Toraja sebagai sebagai varian objek wisata yang dapat menunjang wisata budaya Toraja. Hasil peneliti BMIS ini juga menunjukkan bahwa pemerintah sedang mempersiapkan dan mengembangkan objek-objek wisata agro di Toraja, misalnya wisata agro di Pango-pango Tanah Toraja, wisata agro perkebunan kopi di Toreang di Toraja Utara.

Dalam mengembangkan dan mempromosikan agrowisata di Toraja ke depan, pentingnya pula para stakeholder (pelaku pariwisata) yang bekerja di tour dan travel, di restoran dan hotel) - dibekali dengan 


\section{4 | JURNAL ILMU BUDAY A}

pengetahuan keterampilan bahasa Prancis bidang agrowisata (bahasa Pracis spesifik agrowisata). Pentingnya peningkatan pelayanan bagi wisatawan mancaneara, khususnya berbahasa Prancis mengacu pada kunjungan wisatawan asing (Eropa), di Sulawesi selatan, khususnya di Toraja tahun 2016 didominasi oleh turis yang berbahasa Prancis (Prancis, Swiss, Italia dan Belgia). Tentunya, kedatangan wisatawan mancanegara, khususnya Eropa (Perancis, Belanda, Italia, dan Spanyol) ke daerah wisata Sulawesi Selatan tidak hanya karena daya tarik kekhasan budaya tradisi Toraja tetapi agrowisata dengan memanfaat pemandangan alam dan lahar pertanian, kebun kopi, cengkeh dan menikmati produ-produ agro, misalnya kopi khas Toraja.

Berdasarkan data statistik (www.antaranews.com), jumlah turis mancanegara yang mengunjungi Indonesia sepanjang Januari-Maret 2014 mencapai 2,2 juta orang atau naik 10,07 persen dibandingkan periode yang sama tahun 2013. Pada bulan Maret jumlah wisatawan mancanegara mencapai 765.607 orang dan rata-rata kunjungan wisatawan mancanegara (wisman) per bulan selama triwulan pertama tahun ini sekitar 740.000 orang. Kepala Dinas Kebudayaan dan Pariwisata (Disbudpar) Sulsel Jufri Rahman mengatakan, tahun 2013 proyeksi devisa daerah yang disumbang wisman mencapai USD25 juta (Koran Sindo, 27/2/2014). Badan Pusat Statistik (BPS) Sulsel merilis, pergerakan wisman yang berkunjung ke Sulsel periode Januari hingga Oktober 2013, melejit 32,81 persen menjadi 14.657 dibandingkan tahun lalu. Secara nasional, Makassar menempati posisi keempat dengan persentase kenaikan kunjungan wisman di bawah Lombok 114,04 persen, Yogyakarta 44,71 persen dan Padang dengan kenaikan 32,91 persen. Wisatawan mancanegara yang berkunjung ke Sulawesi Selatan, pada umumnya, berasal dari Prancis dan negara-negara yang menggunakan bahasa Prancis, misalnya Italia, Belanda dan Belgia (negara-negara yang bertetangga dengan Prancis).

Sehubungan dengan hal tersebut, maka salah satu hal yang harus diperhatikan dalam meningkatan pelayanan bagi turis berbahasa Perancis adalah memberikan pengetahuan bahasa Prancis bidang agrowisata bagi strakeholder (tour \& travel) di Makassar yang memiliki paket Tour Toraja.

Perkembangan di bidang sektor pariwisata, tentunya, harus didukung oleh pelayanan prima kepada wisatawan mancanegara, khususnya wisatawan mancanegara berbahasa Prancis. Dan salah satu cara meningkatkan pelayalanan bagi tour dan travel melalui pramuwisata yang melayani langsung turis Perancis yang ada di Makassar adalah pentingnya memiliki pengetahuan dan keterampilan berbahasa Prancis bidang agrowisata.

Dengan pengetahuan dan keterampilan bahasa Prancis bidang agrowisata, hal yang dapat dilakukan oleh stakeholder (tour and travel) pariwisata adalah:

1. Dapat menyusun program program tour sesuai dengan kombinasi budaya tradisi dan agrowisata;

2. Meningkatkan pelayanan dengan memperkenalkan agrowisata yang ada di Toraja.

3. Memperkenalkan dan mengajak turis mancanegara untuk menikmatai produk agrowisata Toraja, misalnya kopi khas Toraja yang diproduksi oleh petani Toraja. 


\section{5 | JURNAL ILMU BUDAYA}

4. Memberikan wawasan kepada turis mancanegara bahwa potensi wisata yang dimiliki Toraja bukan hanya budaya tradisi (Rambusolo) tetapi juga agrowisata.

Tentunya staf di perusahaan stakeholder pariwisata yang perlu dibekali pengetahuan tentan bahasa Prancis bidang agrowisata, sehingga dapat tercapai pelayanan yang memuaskan. Untuk itu, diperlukan suatu metode untuk meningkatkan sumber daya yang bekerja di bidang pariwisata berupa kegiatan pelatihan (workshop) pemahaman dan penggunaan variasi Bahasa Prancis bidang agrowisata sebagai upaya peningkatan pelayanan kepada turis mancanegara khusunya turis Perancis. Kegiatan ini diperuntukkan stakeholder pariwisata (perhotelan dan biro perjalanan wisata di Makassar yang memiliki pelayanan program (paket) tour di Sulawesi Selatan untuk wisatawan mancanegara. Kegiatan pelatihan dilakukan atas kerjasama dengan Himpunan Peramuwisata Indonesia Sulawesi Selatan Makassar, suatu lembaga yang memangani dan melakukan kordinasi dengan pramuwisata yang terdaftra di Sulawesi Selatan.

\section{B. METODE}

Metode merupakan suatu alat dalam pelaksanaan pendidikan, yakni yang digunakan dalam penyampaian materi pembelajaran. Materi pelajaran yang mudah pun kadang-kadang sulit berkembang dan sulit diterima oleh peserta didik, karena cara atau metode yang digunakannya kurang tepat. Namun, sebaliknya suatu pelajaran yang sulit akan mudah diterima oleh peserta didik, karena penyampaian dan metode yang digunakan mudah dipahami, tepat dan menarik (Maesaroh, 2013L 154).

Metode palaksanaan kegiatan adalah berbentuk workshop (pelatihan) dengan mengundang pelaku pariwisata (perusahaan tour dan travel) dan siswasiswi sekolah kejuruan pariwisata di Makassar). Pemateri kegiatan workshop tersebut adalah adalah mereka yang telah memiliki pengalaman di bidang pelayanan pariwisata guide dan dan narasumber yang berprofesi sebagai guide Prancis. Pada kegiatan tersebut peserta diberikan pengetahuan Bahasa Prancis bidang spesifik-agrowisata, berupaka kosa kata dan ungkapanungkapan atau percakapan yang berkaitan dengan pariwisat agro. Workshop dilakukan dengan merode ceramah dan praktik langsung (dialog) yang dibagi atas beberapa kelompok.

Untuk mengukur tingkat pengetahuan bahasa Prancis bidang agrowisata, peserta diberikan pretest (tes awal) dan post tes, setelah melalukan workshop. Pre tes dilakukan untuk mengetahui tingkat pengetahuan bahasa Prancis agrowisata dalam bidang kosakata dan percakapan. Pre test dilakukan untuk mendapatkan gambaran secara umum perilaku peserta sebagai pembelajar pada kegiatan workshop tersebut.

\section{HASIL DAN PEMBAHASAN}

Hasil luaran yang diharapkan dari kegiatan ini adalah dengan pengetahuan keterampilan bahasa Prancis bidang spesifik - agrowisata, para peserta sebagau pelaku pariwisata dapat meningkatkan pelayanan terhadap wisatawan asing.

Untuk meningkatkan kompetensi peserta dalam pelayanan bahasa Prancis bidang agrowisata, dilakukan pretest. Jumlah peserta sebanyak 25 orang dan diberikan tes 


\section{6 | JURNAL ILMU BUDAY A}

Volume 6, Nomor 2, Desember 2018

berupaka kosa kata dan ungkapanungkapan bahasa Prancis bidang agrowisata.

Karakterisitik peserta workshop adalah sebagai berikut: sebanyak $60 \%$ alumni dari Prodi Sastra Prancis program Sarjana, 25\% lulusan diploma pariwisata dan $15 \%$ lulusan SMA yang memperoleh pengetahuan bahasa Prancis melalui kursus.

Karakteristik pekerjaan adalah sebanyak $45 \%$ bekerja sebagai guide freelance (tidak tetap), 25\% bekerja di perusahaan tours dan travel dan sisanya di instansi dinas pariwisata sebagai karyawan.

Setelah diberikan pre test, maka nilai presentasi pengetahuan tentang Bahasa Prancis bidang agrowisata masih di bawah 50\%. Artinya 76\% peserta masih kurang pengetahuan tentang bahasa Prancis agrowisata.

\begin{tabular}{|c|c|c|}
\hline \multirow{2}{*}{ Peserta } & \multicolumn{2}{|c|}{ Nilai } \\
\hline & Kosa kata & Percakapan \\
\hline 1 & 45 & 40 \\
\hline 2 & 45 & 41 \\
\hline 3 & 47 & 42 \\
\hline 4 & 36 & 40 \\
\hline 5 & 32 & 38 \\
\hline 6 & 51 & 45 \\
\hline 7 & 46 & 42 \\
\hline 8 & 45 & 40 \\
\hline 9 & 48 & 42 \\
\hline 10 & 38 & 40 \\
\hline 11 & 41 & 40 \\
\hline 12 & 39 & 41 \\
\hline 13 & 49 & 42 \\
\hline 14 & 43 & 40 \\
\hline 15 & 44 & 40 \\
\hline 16 & 56 & 45 \\
\hline 17 & 45 & 40 \\
\hline 18 & 45 & 42 \\
\hline 19 & 43 & 42 \\
\hline 20 & 45 & 42 \\
\hline 21 & 43 & 40 \\
\hline 22 & 42 & 40 \\
\hline 23 & 42 & 40 \\
\hline 24 & 40 & 45 \\
\hline 25 & 44 & 45 \\
\hline
\end{tabular}

Tabel 1: hasil pre test Bahasa Prancis bidang agrowisata

Hasil pre test menujukkan bahwa mayoritas peserta belum memiliki banyak pengetahuan tentang kosa kata dan percakapan bahasa Prancis bidang agrowisata. Keterbatas pengetahuan kosa kata dan percakapan bahasa Prancis bidang agrowisata tidak terlepas dari program atau paket tour yang selama ini dipilih wisatawan mancanegara, yaitu objek wisata yang berkaitan dengan kematian (kuburan, rumah adat Toraja dan pesta kematian Rambusolo). 


\section{7 | JURNAL ILMU BUDAYA}

Dalam peningkatan kompetensi peserta tentang pengetahuan dan keterampilan berbahasa Prancis bidang agrowisata dilakukan dua metode, yaitu metode ceramah dan praktik langsung di kelas (ruang workshop). Metode ceramah merupakan sebuah bentuk interaksi melalui penerangan dan penuturan



Gambar 1: Pelaksanaan Pelatihan

Ada pun kosa-kosa bahasa Prancs yang diberikan berkaitan dengan agrowisata yaitu:

- Culture du café (budidaya Kopi)

a. Kata benda penting dalam budidaya kopi

1. Caféier (pohon kopi)

2. Plantation du café (perkebunan kopi)

3. Cerise du café (buah kopi)

4. Noyau du café (inti buah kopi yang terdiri dari sepasang biji)

5. Grain du café (biji kopi)

6. Grain du café vert (biji kopi hijau)

7. Grain du café torréfié (biji kopi sangrai)

b. Kata kerja penting dalam proses

budidaya kopi

1. Planter (menanam)

2. Cultiver (mengolah lahan dan merawat tanaman) secara lisan oleh seorang guru terhadap siswa di kelasnya (Beni, Soesanto \& Samsudi, 2009:79).

Metode ceramah dilakukan untuk memaparkan secara deksriptif kosa-kosa kata dan percakapanpercakapan yang berhubungan dengan bahasa Prancis bidang agrowisata.



Gambar 2: Praktik Berbicara dalam bidang bahasa Prancis agrowisata

3. Récolter (memanen)

4. Cueillir (memetik)

5. Traiter (mengolah)

6. Éplucher (mengupas)

7. Sécher (mengeringkan)

8. Torréfier (menyangrai)

9. Mouliner (menggiling)

- Culture du cacao (budidaya coklat)

a. Kata benda penting dalam budidaya coklat

1. Cacaoyer (pohon coklat)

2. Plantation de cacao (perkebunan coklat)

3. Cabosse de cacao (buah coklat)

4. Fève de cacao (biji coklat)

5. Fève de cacao torréfié (biji coklat sangrai)

b. Kata kerja penting dalam proses budidaya coklat

1. Planter (menanam)

2. Cultiver (mengolah lahan/merawat tanaman)

3. Récolter (memanen) 


\section{8 | JURNAL ILMU BUDAY A}

Volume 6, Nomor 2, Desember 2018

4. Cueillir (memetik)

5. Écabosser (membelah buah coklat)

6. Sécher (mengeringkan)

7. Torréfier (menyangrai)

8. Mouliner (menggiling)

- Culture de clou de girofle (budidaya cengkeh)

a. Kata benda penting dalam budidaya cengkeh

1. Giroflier (pohon cengkih)

2. Plantation du clou de girofle (kebun cengkih)

3. Fleur de girofle (bunga cengkih)

4. Clou de girofle (cengkih)

5. Clou de girofle sec (cengkih kering)

b. Kata kerja penting dalam budidaya cengkih

1. Planter (menanam)

2. Cultiver (cultiver)

3. Récolter (memanen)

4. Cueillir (memetik)

5. Sécher (mengeringkan)

6. Extraire (mengekstrak)

- Culture de riz/ riziculture (budidaya padi)

a. Kata benda penting dalam budidaya padi

1. Plante de riz (tanaman padi)

2. Rizière (sawah)

3. Grain de riz (biji padi)

4. Panicule (untaian padi)

5. Buffle d'eau (kerbau)

b. Kata kerja penting dalam budidaya padi

1. Planter (menanam)

2. Cultiver (mengolah lahan/merawat tanaman)

3. Labourer (membajak)

4. Récolter (memanen)

5. Couper (memotong)

6. Battre (mengirik)

7. Vanner (memilah)

8. Peler (mengupas kulit padi)

- Kosakata dunia Café (Warung Kopi)

\section{a. Jenis-jenis minuman kopi}

1. Le café filtre : kopi saring

2. L'expresso : kopi espresso

3. Le café Viennois (espresso con panna) : kopi espresso ditambah whipped cream di atasnya.

4. Le café noisette: kopi espresso yang ditambahkan busa susu sehingga warnanya menyerupai hazzelnut.

5. Le café américain (caffè americano) : kopi espresso yang ditambah air panas lagi.

6. Le café allongé : kopi encer

7. Le café frappé : es kopi

8. Le café au lait : kopi susu $(60 \%$ kopi, $40 \%$ susu)

9. Le café renversé : susu kopi (60\% susu, $40 \%$ kopi)

10. Le cappuccino : kopi berbahan dasar espresso dicampur busa susu ditaburi bubuk coklat

11. Le mocca (moccacino): kopi berbahan dasar espresso dicampur busa susu, dicampur coklat dan krim, lalu ditabur bubuk kayu manis.

- Peralatan membuat kopi

1. Cafetiere à piston

2. Cafetière à filtre

3. Cafetière italienne

4. Moulin à café

- Profesi per-café-an

1. Barista: peracik kopi

2. Torréfacteur : tukang sangrai kopi

Ada pun Karakter atau stereotip umum wisatawan Prancis dalam hubungan dengan percakapan adalah : 1. Sangat memperhatikan jadwal

Contoh pertanyaan yang sering muncul:

"Nous avons quel programme aujourd'hui?" 


\section{9 | JURNAL ILMU BUDAY}

" Nous allons aux plantations de café à quelle heure?"

2. Ingin mengetahui alasan atau proses segala sesuatu

Contoh pertanyaan yang sering muncul:

"Pourquoi on ne profite pas les buffles d'eau?"

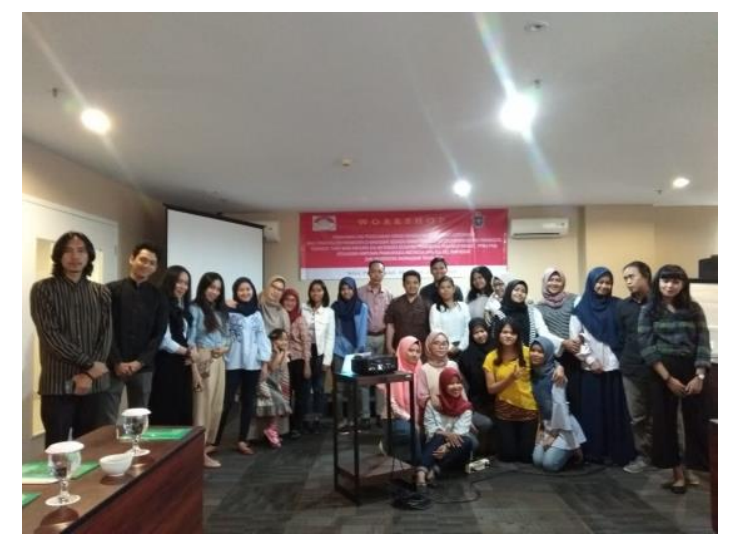

Gambar 3: Foto bersama dengan stakeholder dan narasumber sumber

Setelah diberikan pelatihan oleh nara sumber tentang pemahaman dan penggunaan kosa-kata bidang agrowisata dalam bahasa Prancis, maka langkah selanjutnya yang dilakukan adalah meningkatkan kemampuan berkomunikasi (production orale) dalam bahasa Prancis dengan menggunakan kosa-kata bidang agrowisata. Peningkatan kemampuan berbicara dilakukan melalui praktik yang dilakukan secara berkelompok dan setiap anggota kelompok memiliki peran dan kesempatan untuk berbicara.

Hasil praktik berbicara dengan menggunakan kosa-kata bidang agrowisata bahasa Prancis menunukkan kemampuan mengkomunikasikan secara lisan kosa-kata bidang agrowisata. Untuk mengetahui efektifitas pelatihan penggunaan variasi bahasa melalui kosa-kata bidang agrowisata, maka dilakukan post test.
"Comment on traite le café ici?"

3. Senang dengan angka-angka statistik

Contoh pertanyaan yang sering muncul:

"Il y a combien d'habitants ici?"

"On récolte combien de fois par an?"

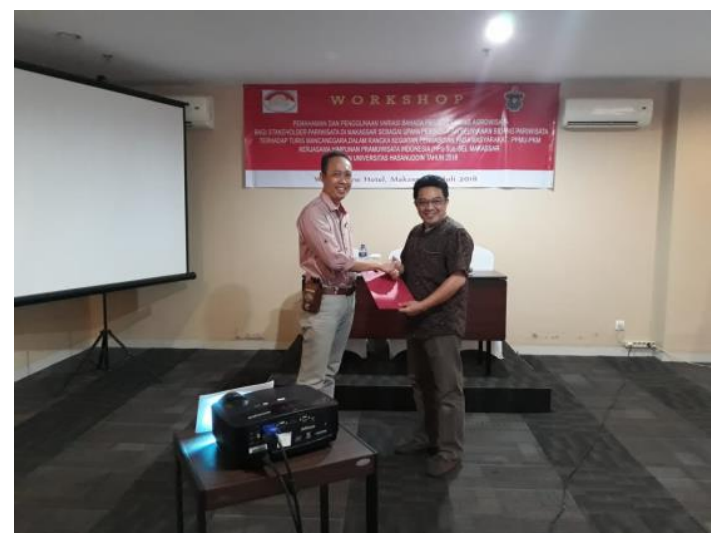

Gambar 4: Pemberian Cendramata kepada Mitra, Ketua Himpunan Pramuwisata Indonesia Sulawesi Selatan

\begin{tabular}{|c|c|c|}
\hline $\begin{array}{r}\text { Hasil } \\
\text { eningkatan }\end{array}$ & $\begin{array}{l}\text { post } \\
\text { secara }\end{array}$ & $\begin{array}{r}\text { menunjukk } \\
\text { signifik }\end{array}$ \\
\hline $\begin{array}{l}\text { penguasaan } \\
\text { agrowisata }\end{array}$ & $\begin{array}{l}\text { variasi } \\
\text { bahasa }\end{array}$ & $\begin{array}{l}\text { bahasa } \\
\text { Prancis. }\end{array}$ \\
\hline
\end{tabular}
presentasi pengetahuan dan penguasaan variasi bahasa bahasa Prancis bidang agrowisata sangat baik, dengan nilaia rata 86. Praktik berbicara bidang agrowisata melalui penggunaan kosakata merupakan metode yang sangat efektif untuk meningkatkan penguasaan kosa-kata dalam bidang spesifik (agrowisata).

\section{KESIMPULAN}

Variasi bahasa Prancis bidang agrowisata merupakan pengetahuan dan keterampilan praktik berbahasa Prancis di lapangan bagi stakeholder pariwisata. Variasi bahasa ini mencakup kosa-kata dan percakapan bahasa Prancis. Penerapan metode pembelajaran bahasa 


\section{0 | JURNAL ILMU BUDAYA}

Volume 6, Nomor 2, Desember 2018

Prancis dengan penggunaan variasi bahasa Prancis bidang agrowisata melalui pelatihan memberikan pengalaman baru bagi stakeholder dan meningkatkan kompetensi dalam bidang bahasa Prancis agrowisata. Hasil post tes setelah pembekalan pengetahuan variasi bahasa Prancis agrowisata menunjukkan adanya peningkatan kemampuan bekomunikasi secara lisan dalam bidang bahasa Prancis agrowisata. Peserta lokakarya telah memahami dengan baik penggunaan kosa-kosa bahasa Prancis agrowisata, begitu pun percakapan yang dapat dipraktekkan dengan lancar.

\section{DAFTAR PUSTAKA}

Hasyim, Muhammad, Dr., M.Si., Akhmar, Andi Muhammad, Dr., M.Hum, Hasbullah, Drs., M.Hum, dan Wahyuddin, S.S., M.Hum. Pengembangan pariwisata di Toraja (Hasil Penelitian BMIS 2016 LP2M Unhas. Makassar: LP2M Unhas. Harsono, Beni, Soesanto, \& Samsudi. 2009. Perbedaan Hasil Belajar
Antara Metode Ceramah Konvensional Dengan Ceramah Berbantuan Media Animasi Pada Pembelajaran Kompetensi Perakitan dan Pemasangan Sistem Rem. "Jurnal PTM" Volume 9, No. 2.

Maesaroh, Siti. 2013. Peranan Metode Pembelajaran Terhadap Minat Dan Prestasi Belajar Pendidikan Agama Islam. "Jurnal Kependidikan", Vol. 1 No. 1. P. $150-168$

I Gde Pitana \& I Ketut Surya Diarta.2009. Pengantar Ilmu Pariwisata. Yogyakarta : Andi Publishing

Oka A. Yoeti. 1996. Pengantar Ilmu Pariwisata. Bandung: Angkasa

Oka A. Yoeti. 2003. Tours and Travel Marketing. Pradnya Paramita. Jakarta

Oka A. Yoeti. 2002. Perencanaan Strategis Pemasaran Daerah Tujuan Wisata. Jakarta: Pradnya Paramita

Suyitno. 2001. Perencanaan Wisata, Tour Planning. Yogyakarta: Kanisius 